\title{
LIMITES E POSSIBILIDADES DA CONTRIBUIÇÃO DO PROGRAMA SALA DE LEITURA NA FORMAÇÃO DE LEITORES NO CONTEXTO ESCOLAR
}

\section{LIMITS AND POSSIBILITIES OF THE CONTRIBUTION OF THE READING CLASSROOM PROGRAM IN THE YOUNG READERS FORMATION INSIDE THE SCHOOL CONTEXT}

\author{
Ana Carolina Palma Francisco Ávila *
} Cláudio Marcondes de Castro Filho ${ }^{* *}$

\begin{abstract}
Resumo: Ancorado na abordagem Histórico-cultural, trata-se de um estudo de caso e representa uma investigação qualitativa cujo objetivo é discutir acerca das possibilidades e limites da contribuição do Programa Sala de Leitura para a formação de leitores no contexto escolar. O lócus escolhido para a aplicação da pesquisa foi a sala de leitura Clarisse Lispector, sediada na Escola Estadual Professora Djanira Velho, município de Ribeirão Preto/SP. A coleta de dados foi efetuada através de entrevista semiestruturada e interações via grupo focal, realizadas, respectivamente, com a mediadora da sala de leitura e com os sete alunos integrantes da amostra. Identifica e descreve as práticas que ocorrem na sala de leitura. Os resultados reconhecem as potencialidades da sala de leitura na formação leitora dos educandos e aponta os limites a serem superados mediante sugestões que se apoiam na oferta de momentos de leitura livre e no ensino de estratégias de leitura.
\end{abstract}

Palavras Chave: Formação de leitores. Práticas de leitura. Programa Sala de Leitura.

Abstract: Based in the Cultural Historical approach as a theoretical framework, the research is based in a case study and represents a qualitative investigation which its general objective is to discuss the possibilities and limits of the contribution of the Reading Classroom Program into forming readers in the school context. The place chosen to develop the research was the reading class Clarice Lispector, at the Professora Djanira Velho, a public school in the city of Ribeirão Preto and linked to the São Paulo State Department of Education. The data collection was performed through a semi-structures interview and interactions via focus group, carried out, respectively, with the reading classroom mediator and the seven sample students. The results recognizes the potential of the reading classroom in reading education of the students and points out the limits to be overcome through suggestions that offer free reading moments and the teaching of reading strategies.

Keywords: Readers formation. Reading practice. Reading Classroom Program.

\section{Introdução}

Desde 2009, o Programa Sala de Leitura tem demarcado seu território nas escolas da rede estadual paulista e, neste sentido, pode representar um espaço de incentivo e motivação para as práticas de socialização em torno da leitura, vislumbrando, então, um alargamento do horizonte de oportunidades do contato com a leitura e com o livro que vão além das práticas cotidianas de leitura em sala de aula.

De acordo com a Resolução SE $n^{\circ}$ 76/2017, a sala de leitura objetiva oferecer:

I - oportunidade de acesso a livros, revistas, jornais, folhetos informativos, catálogos, vídeos, DVDs, CDs e outros recursos complementares;

\footnotetext{
* Mestranda do Programa de Pós Graduação em Educação da Faculdade de Filosofia Ciências e Letras da Universidade de São Paulo. carolpallma@usp.br

** Doutor em Ciências da Informação pela Universidade de São Paulo. Professor de Ciências da Informação na Universidade de São Paulo. claudiomarcondes@ffclrp.usp.br
} 
II - incentivo à leitura como principal fonte de informação e cultura, lazer e entretenimento, comunicação, inclusão, socialização e formação de cidadãos críticos, criativos e autônomos.

Pelo apresentado, o Programa Sala de Leitura dá condições para a criação de um espaço privilegiado de acesso à leitura, disponibilizando o acesso a materiais de leitura variados e garantindo a permanência de um professor visando o cumprimento de seu funcionamento, cujo objetivo maior está atrelado à formação do leitor crítico, criativo e autônomo, como propõe sua legislação.

Não há sala de leitura sem que haja um professor responsável por seu funcionamento, devendo este participar de orientações técnicas, das reuniões de trabalho pedagógico coletivo realizadas na escola, além de elaborar projetos de trabalho que incentivem a leitura dentre outras atribuições. Desta forma, a hipótese sustentada é a de que as possíveis contribuições do Programa Sala de Leitura estão embasadas na atuação do professor que planeja e oferece aos educandos a oportunidade de participar de práticas de leitura, podendo assim representar um referencial positivo no processo de formação do leitor. Nesse sentido, a problemática deste estudo de caso procura averiguar se as práticas da sala de leitura Clarice Lispector estão sendo capazes de proporcionar aos educandos o pleno desenvolvimento de uma formação leitora.

Trata-se, portanto, de um programa de leitura encabeçado pela Secretaria da Educação do Governo do Estado de São Paulo e pelo Instituto Ayrton Senna, que transformou os espaços antes destinados às abandonadas bibliotecas em salas de leitura, geridas por professores e cujo apoio técnico-pedagógico da Diretoria de Ensino está previsto em resolução legal. Apesar das críticas contundentes à histórica desvalorização da biblioteca e do profissional bibliotecário e diante da situação na qual se encontram as bibliotecas escolares, o Programa Sala de Leitura pode ser entendido, a priori, como uma demonstração de interesse do governo estadual no desenvolvimento de políticas públicas de fomento à leitura e à formação de leitores no contexto escolar.

\section{A escola e a leitura na perspectiva da teoria histórico cultural}

Propondo uma Teoria Histórico-cultural, Vygotsky se interessava-se "no funcionamento cognitivo do ser humano, enquanto parte de uma realidade histórica" (VYGOTSKY, 2016, p. 15), considerando, assim, a relação intrínseca entre os aspectos socioculturais e os aspectos biológicos na constituição dos indivíduos. Desta forma, o repertório conceitual da Teoria Histórico Cultural compreende que o desenvolvimento do homem e de suas capacidades psicológicas superiores ocorrem mediados pelas interações sociais e pela ação intencional dos homens entre si, colocando o aspecto sociocultural como parte essencial da constituição da natureza humana.

O conceito de mediação é essencial para compreendermos os aspectos sóciohistóricos do funcionamento psicológico. Um dos pressupostos da teoria vygotskyana é que a relação do homem com o mundo não se dá de forma direta, já que se trata de uma "relação mediada, sendo os sistemas simbólicos os elementos intermediários entre o sujeito e o mundo". (OLIVEIRA, 2011, p. 17). A contribuição do outro, a partir das relações sociais, ocorre no âmbito da linguagem, por isso, o uso dos signos, como instrumento psicológico e sistema simbólico, torna-se necessidade e condição para o desenvolvimento social humano. Os signos são instrumentos psicológicos que coordenam e controlam as ações psicológicas. 
A invenção e o uso dos signos como meios auxiliares para solucionar um dado problema psicológico (lembrar, comparar coisas, relatar, escolher, etc.), é análoga à invenção e uso de instrumentos, só que agora no campo psicológico. O signo age como um instrumento da atividade psicológica de maneira análoga ao papel de um instrumento no trabalho. (VYGOTSKY, 1984, p. 59-60 apud OLIVEIRA, 2011, p. 21).

Dispondo dos signos como instrumentos psicológicos a humanidade foi capaz de favorecer e direcionar seu desenvolvimento cultural. A atividade de significação, portanto, modifica o processo de desenvolvimento do psiquismo humano possibilitando a expressão do pensamento e de todas outras funções psicológicas superiores. Sendo assim, as aprendizagens e o desenvolvimento das capacidades psicológicas superiores são processos mediados do nível interpsicológico para nível intrapsicológico, através de sistemas simbólicos como, por exemplo, a linguagem. Por sua vez, a leitura, pela sua atividade intensa com os signos, revela-se como uma das vias mais interessantes no processo de construção do pensamento e da formação cultural do sujeito.

Na Teoria Histórico-cultural a ênfase creditada às relações sociais confere uma perspectiva interacionista ao processo de desenvolvimento do indivíduo, pois as influências sociais estarão sempre presentes. Assim, através das relações sociais mediadas pela linguagem, ocorre o desenvolvimento cultural do indivíduo. Dada a importância da linguagem neste processo e entendendo a leitura como atividade inerente ao uso dos signos e da linguagem, podemos considerar as práticas de leitura propostas nas escolas uma oportunidade de oferecer ao educando elementos culturais para fomentar seu desenvolvimento.

Consequentemente, a participação da escola nesse processo é de suma importância, pois as práticas culturais de leitura, escrita, cálculo, desenho, entre outras, são socialmente adquiridas, ou seja, demandam que as relações sociais lhes sirvam como meios externos, demonstrando a dialética entre a atividade psíquica e o meio sociocultural. Na escola, o aprendizado desperta o desenvolvimento e ambos dependem da ação intencional do professor, que é entendido como um facilitador do processo de mediação cultural, ancorado no signo linguístico, na linguagem e na palavra em processo de comunicação.

O objetivo da escola, portanto, deve ser o desenvolvimento de um leitor crítico, que busca no ato da leitura alimentar-se dos signos, das palavras que lhes servirão para a construção de seu pensamento, de sua personalidade, das suas vivências e dos sentidos que elas despertam.

\section{As práticas da sala de leitura Clarice Lispector}

As práticas de leitura podem ser abordadas por tradições de investigações pedagógica, histórica sociológica, linguística - que, embora diferentes, podem ser complementares e não excludentes. Percebe-se assim a dimensão interdisciplinar e a inevitável diversificação teórico-metodológica atribuídas aos estudos das práticas de leitura. Sendo assim, as pesquisas sobre as práticas de leitura circunscrevem-se tanto ao domínio do ato de ler propriamente dito - textos, gêneros e suportes em torno dos quais esse ato se realiza - quanto das significações plurais que, no contato com o texto, os leitores produzem. Por isso, a apreensão das condições deste inter-relacionamento dos dois componentes centrais de toda leitura - texto e leitor - tem sido uma das principais referências dos estudos sobre práticas de leitura dos últimos anos. (BATISTA; 
GALVÃO, 2011, p. 22). O texto é imóvel, instável, não oferece por si só sua significação, pois pressupõe a atuação do leitor na produção de sentidos e percepções.

(...) o leitor não apreende meramente um sentido que está lá; o leitor atribui sentidos ao texto. Ou seja, considera-se que a leitura é produzida e se procura determinar o processo e as condições de sua produção. Dai se pode dizer que a leitura é o momento crítico da constituição do texto, o momento privilegiado do processo de interação verbal, uma vez que é nele que se desencadeia o processo de significação. (ORLANDI, 1988, p. 38).

O autor, portanto, não é o único a guiar os sentidos de um texto, que se diversificam tendo em vista as práticas de leitura e os seus leitores, que por sua vez, estão submetidos às múltiplas determinações que organizam o espaço social. Autores, leitores e textos não são neutros, tampouco independentes das esferas materiais e das condições sociais nas quais são produzidos e lidos.

Já na tradição sociológica e histórica, a pesquisa com práticas de leitura propõe investigar quem lê, o quê lê, quando, onde, por que motivos, de que modos, com que intensidade lê. (CHARTIER, 2011, p. 10-12); e apreender processos de natureza técnica e de natureza social que interferem na ampliação do público leitor, nos modos de ler, nas maneiras de atribuir sentido, na própria organização da página, do impresso, de seus suportes (CHARTIER, 2011, p. 10-12).

Neste artigo, realizaram-se a identificação e descrição das principais práticas de leitura desenvolvidas pela professora mediadora da sala de leitura Clarice Lispector bem como a verificação dos sentidos, vivências e experiências que tais práticas despertaram nos educandos participantes da amostra. É importante frisar que a coleta destas informações foi possível a partir do grupo focal realizado com sete educandos, ativos frequentadores da sala de leitura, e da entrevista com a professora.

\subsection{Todos juntos contra o Aeds aegypti}

Projeto realizado anualmente e direcionado aos educandos do Ensino Fundamental II. De modo geral, consiste em distribuir panfletos para conscientizar a vizinhança da escola acerca da necessidade de exterminar os focos do mosquito transmissor da dengue. Na primeira etapa do projeto os alunos produzem os panfletos que buscam conscientizar sobre as ações necessárias para se evitar a doença. $\mathrm{Na}$ segunda etapa, distribuem nas residências do entorno escolar. O trabalho é realizado com a colaboração e orientações das professoras de português e ciências para confecção de panfletos.

\subsection{Setembro Amarelo}

De ocorrência anual, é realizado em parceria com a turma da Faculdade de Enfermagem da USP/RP como parte de uma campanha sobre saúde metal e adolescência. São realizadas palestras com os estagiários da faculdade de Enfermagem e posterior produção de textos e cartazes com auxilio da sala de leitura. Desta forma, a preocupação com a saúde mental foi o tema da realização de um varal de textos cujas mensagens sinalizavam a expressão da dor que envolve os estados mentais da depressão e da ansiedade e como podem ser sentidos, compreendidos e superados. 


\subsection{Mediação e Linguagem}

De ocorrência anual, é um dos projetos internos da Secretaria da Educação do Estado de São Paulo em que todos os professores mediadores da rede são convocados a participar. Consiste na adaptação de obras literárias para a linguagem audiovisual em vídeos de um minuto.

Aos alunos cabe escolher a obra que desejam, organizar os grupos, realizar a leitura, selecionar o trecho a ser adaptado ou adaptar a obra inteira, criar o roteiro, realizar as filmagens ou selecionar imagens, configurar e editar o vídeo para o envio. Quatro dos sete educandos que integram o grupo focal desta pesquisa participaram deste projeto no ano de 2017, cujos resultados foram duas adaptações: da obra Dom Quixote e de um trecho da Odisseia, de Homero. Sobre esta experiência a aluna 7 declara durante o grupo focal:

Quando nós estávamos desenvolvendo o projeto da Odisseia eu lembro que eles (apontando para os colegas) deram apoio pra gente e eles estavam falando sobre Dom Quixote e eles desenvolveram o vídeo e a gente foi conversando sobre a história e a gente compartilhava...eu sempre quis saber sobre o Dom Quixote mas nunca tinha pegado no livro... e enquanto eles falaram, gravavam o vídeo e montavam eu pude saber um pouco mais do livro e me deu muita curiosidade de ler (aluna 7, grupo focal).

O projeto coloca os educandos em contato com um diálogo entre a literatura e o audiovisual, permitindo que o sujeito leitor interfira na obra, adaptando-a a linguagem audiovisual e permitindo a inserção de aspectos subjetivos ligados à expressão dos sentidos. O relato de vivência acima mostra que a curiosidade por uma obra nem sempre levará o leitor a "pegar no livro", mas que compartilhar conversas sobre as obras ou inseri-las em projetos que mobilizem o leitor ao contato e à experiência pode ser um fator iniciativo do processo de formação de leitores.

\subsection{Leitura de crônicas e contos}

Ocorre bimestralmente e atinge os educandos dos anos finais do Ensino Fundamental e do Ensino Médio. Após a leitura de crônicas e contos sugeridos pela professora, os educandos tem a oportunidade de expressar, em diferentes linguagens, os sentidos e as experiências despertados pelo texto. Durante o grupo focal, o aluno 2 relatou sua experiência com este projeto:

(...) a gente fez um vídeo de terror, onde tínhamos que ler contos de terror e criar uma história com aquilo... foi legal fazer isso, porque teve a participação das pessoas do grupo, você via que as pessoas estavam realmente animadas para fazer aquela atividade e isso acabou se tornando uma forma de prazer fazer aquilo...por meio da leitura... a gente acabou vendo a leitura não como uma obrigação de coisas a fazer mas como um prazer (Aluno 2, grupo focal).

Nessa prática, a experiência da leitura ampliou o repertório verbal e não verbal do educando, colocando-o em contato com a relação de intertextualidade entre os textos verbais e não verbais. A leitura dos contos e sua posterior apropriação na produção dos 
vídeos permitiram ao educando reforçar ou metamorfosear novos sentidos produzidos ao longo do processo de interação entre os educandos, os textos e a linguagem audiovisual. Como afirma Orlandi (1984, p.40),

A convivência com a música, a pintura, a fotografia, o cinema, com outras formas de utilização do som e com a imagem, assim como a convivência com as linguagens artificiais poderiam nos apontar para uma inserção no universo simbólico que não é a que temos estabelecido na escola. Essas linguagens todas não são alternativas. Elas se articulam. E é essa articulação que deveria ser explorada no ensino da leitura, quando temos como objetivo trabalhar a capacidade de compreensão do aluno. (ORLANDI, 1984, p. 40).

Em outro exemplo, a leitura da crônica Segurança, de Luís Fernando Veríssimo, permitiu a criação de um painel, exposto na sala de leitura Clarice Lispector, com desenhos, expressões e registros da representação que os educandos fizeram dos sentidos despertados pelo texto. Tendo em vista que a linguagem não verbal predomina entre os jovens, a fala do Aluno 2 mostra que permitir a expressão do educando, respeitando-se as diferentes linguagens que constituem seu universo simbólico, tornou possível que o ato da leitura fosse associado a momentos de interação, animação e prazer, em contraposição à obrigatoriedade característica de algumas práticas de leitura escolares.

\subsection{Roda de Leitura}

Projeto realizado bimestralmente e direcionado aos sextos e sétimos anos, etapas iniciais do Ensino Fundamental II na qual há intervenção direta da professora da sala de leitura com relação ao empréstimo de livros. É distribuído aleatoriamente em uma grande mesa certa quantidade de livros selecionados pela professora. Os alunos devem circular pela mesa e folhear os livros. O objetivo é que eles passem um tempo observando e lendo as informações escrita e visual contidas na capa e por fim, escolham um exemplar que deverá ser emprestado, com devido registro no caderno de empréstimo da sala de leitura. No próximo encontro acontece a roda de leitura, que consiste na disposição dos alunos em círculo, a fim de que possam escutar e visualizar uns aos outros enquanto comentam sobre suas leituras e respondem perguntas da professora mediadora. Segundo a professora, nesta prática de leitura ela consegue trabalhar a oralidade e a expressão corporal, pois é possível perceber "aquele que tem facilidade de contar o que leu, aquele que tem muita dificuldade, aquele que é tímido, aquele que não tem desenvoltura alguma por ter alguma dificuldade em interpretação e, assim, foco mais nesses para ajudá-los", ela declarou. A prática é uma oportunidade para socializar a leitura realizada, compartilhando suas apreciações pessoais, comentando o prazer ou o desprazer causado pela obra.

\subsection{Constelação}

Projeto realizado bimestralmente e direcionado aos sexto e sétimo anos. Os educandos são chamados a escolherem livremente um livro para leitura em casa. Devem também customizar um caderno, colocando na capa o nome do projeto "Constelação". Depois de lido o livro, os educandos devem recontar a estória e fazer um resumo que 
conste desde as informações sobre o nome do autor, dos personagens principais, suas características até sobre os sentimentos que o livro despertou, podendo se expressar também através de ilustrações.

A cada nova leitura comentada o aluno é agraciado com uma estrela no caderno. Os registros de leitura, por sua vez, podem ajudar a diagnosticar e orientar os alunos quanto a suas dificuldades de leitura. Eventualmente, a verificação do caderno pela a professora de português pode ocorrer com fins avaliativos. O projeto finaliza quando os alunos se reúnem em uma roda de leitura onde podem tecer seus comentários, perguntar e expressar suas impressões sobre a obra lida.

Como aponta Cosson (2018, p. 121), o comentário é talvez uma das formas mais antigas de se relacionar com o texto escrito. Por isso, é importante observar que tanto a Roda de Leitura quanto o projeto Constelação são práticas aonde o educando exerce a possibilidade de comentar sobre a obra. Os dois projetos culminam com a reunião dos educandos para comentar as obras lidas. No projeto Constelação, o comentário no caderno é uma prática individual, muito semelhante à prática do diário de leitura.

Nos termos das práticas de leitura do comentário, o diário de leitura é um registro das impressões do leitor durante a leitura do livro, podendo versar sobre dificuldades de compreensão de determinadas palavras e trechos, transcrição de trechos favoritos com observações, evocação de alguma vivência, relação com outros textos lidos, apreciação de recursos textuais, avaliação das ações dos personagens, identificação de referencias histórica e tantos outros recursos que constituem a leitura como um diálogo registrado entre leitor e texto. (COSSON, 2018, p. 122).

Compartilhar coletivamente comentários, impressões, observações, trechos favoritos e relações extraídos do texto lido "torna possível beneficiar-se da competência dos outros para construir o sentido e obter o prazer de entender mais e melhor os livros" (COLOMER, 2007, p. 143). Tanto a Roda de Leitura quanto o projeto Constaleção oportunizam aos educandos a discussão sobre livros em grupo, o que favorece o processo de compreensão e interpretação do texto. Como afirma Colomer:

(...) compartilhar a leitura significa socializá-la, ou seja, estabelecer um caminho a partir da recepção individual até a recepção no sentido de uma comunidade cultural que interpreta e avalia. A escola é o contexto de relação onde se constrói essa ponte e se dá ao aluno a oportunidade de atravessá-la. (COLOMER, 2007, p. 147).

Ambos os projetos apresentam características muito semelhante ao que Cosson denomina de círculo de leitura (COSSON, 2018). Trata-se, resumidamente, de favorecer a criação de uma comunidade interpretativa a partir da prática de compartilhamento coletivo e colaborativo de leituras e diálogos em torno de uma obra escolhida. Segundo Cosson (2018, p. 41), a proposta desta prática consiste no envolvimento dialógico dos quatro elementos que compõem um círculo de leitura: o leitor, autor, texto e contexto. Sua importância está na situação de interação social em torno da discussão coletiva de uma obra, que coloca o educando como participante de uma comunidade de leitores. Cosson (2018, p. 145) reitera que os círculos de leitura e outras práticas semelhantes não possuem forte componente instrucional, sendo necessário serem complementados com outras práticas, dependendo dos objetivos do professor. De acordo com Cosson 
(2018, p. 139-147), além de contribuir com a formação de leitores, os círculos de leitura proporcionam:
a) Estreitar os laços sociais entre os educandos;
b) Explicitar o caráter social da interpretação dos textos;
c) Maior envolvimento dos educandos com o texto;
d) Desenvolvimento do pensamento crítico;
e) Empoderamento do educando no processo de escolha dos livros e comando das discussões;
f) Reforço das identidades;
g) Aprendizagem mediada pelos próprios educandos;
h) Riqueza de interpretação por força da diversidade de pontos de vistas
i) Desenvolvimento da compreensão dos textos, etc.

Os círculos de leitura e outras práticas semelhantes podem se estender a todas as etapas de ensino, pois nessa interação com a leitura, os educandos percebem-se participantes de um movimento socialmente dinâmico de atribuição de sentidos, já que nossas leituras "são construídas dentro do jogo de forças de uma comunidade e que é por meio da participação nessa comunidade que nos constituímos como leitores" (COSSON, 2018, p.138).

\subsection{Livro que anda}

Direcionado aos alunos do Ensino Médio e realizado semestralmente, o projeto inicia-se com a participação dos educandos na pesquisa das obras nas estantes do acervo que vão compor a seleção dos textos. A escolha é realizada pelos educandos, fundamento básico para que exerçam seu protagonismo. A função da professora é de sugerir e orientar as decisões dos educandos. Além disso, o participante deve confeccionar um crachá de apresentação com o nome do projeto "Livro que Anda", que deve ficar anexado ao pescoço enquanto ele participa da prática. Os educandos transformam-se, então, em livros que andam. Os participantes andam tanto no ambiente escolar (recreio, festas escolares) como em diferentes locais públicos (praças, teatros, pontos de ônibus, etc.) abordando pessoas e oferecendo-lhes a oportunidade de ouvir uma leitura, geralmente uma declamação de poesia, um conto ou uma crônica. Os alunos podem atuar em grupos a partir da leitura de um mesmo livro, intercalando a leitura entre o grupo; ou cada qual no grupo com um livro diferente oferecendo a possibilidade de escolha ao leitor ouvinte.

Uma adaptação desta prática é o grupo teatralizar a leitura tal como um coro falado. Segundo Cosson, "trata-se da recitação conjunta de um poema ou texto narrativo em que o som das vozes se alterna ou é emitido em uníssono, com ou sem acompanhamento musical". (COSSON, 2018, p. 109). O autor afirma que nesta prática de leitura o educando tem a oportunidade de aprimorar a elocução e a pronúncia, de ampliar o vocabulário, desenvolver a leitura intensiva e promover diferentes formas $\mathrm{d}$ interpretação.

Com efeito, ao se apropriar do texto para recitá-lo, o leitor precisa construir um sentido que vai guiar sua voz, precisa interpretar o texto para poder guardá-lo no coração. Neste sentido, é preciso compreender que, no coro falado, os alunos não estão apenas aprendendo sobre poesia, "os alunos estão fazendo poesia; eles estão 
entrando no mundo do poema para comunica-lo, para expressá-lo, por isso participar de um coro falado leva à experiência direta com o texto literário" (COSSON, 2018, p. 109-110).

O processo de memorização, o posicionamento, a postura, a ênfase em determinados trechos, a entonação da voz e o ritmo da fala são, portanto, elementos que contribuem na construção dos sentidos de um texto. Apoiado em Trousdale e Harris, Cosson $(2018$, p. 110) sugere um planejamento para esta prática: iniciar com a leitura individual e silenciosa do texto, seguida da leitura coletiva e em voz alta, discussão entre os membros do grupo sobre a compreensão e os sentidos despertados pelo texto e por fim, a interpretação.

\subsection{Amar se aprende amando}

Projeto realizado anualmente e direcionado aos alunos do Ensino Médio. Os educandos escolhem as obras que desejam no acervo e a partir delas contam estórias, apresentam peças de teatro ou declamam poesias em asilos, orfanatos ou associações como a Casa do Vovô e a ADEVIRP (Associação dos Deficientes Visuais de Ribeirão Preto).

A partir da leitura é possível estabelecer um contato inicial com o outro que, aberto à escuta da leitura, sente também a chance de ser ouvido. Na entrevista, por exemplo, a professora da sala de leitura afirma que, nas visitas ao asilo, assim que terminada a leitura promovida pelos alunos, alguns dos idosos continuavam a "contação de estórias" narrando suas próprias experiências de vida. Além disso, afirma que nas visitas à associação de deficientes visuais, os alunos visitantes leem em voz alta, mas também ouvem a leitura feita pelos frequentadores da instituição, tendo em vista que a Associação dos Deficientes Visuais de Ribeirão Preto oferece a oportunidade da aprendizagem da escrita e da leitura em braile. Para a maioria dos alunos visitantes é o primeiro contato com o braile, a linguagem escrita dos deficientes visuais.

O diferencial do projeto é fazer da leitura o cerne do encontro dialógico entre os educandos com o mundo fora dos muros da escola. Os relatos de vivência dos alunos indicam que se sentiram profundamente tocados com o contato tanto com os idosos quanto com os deficientes visuais. Os trechos abaixo ilustram os sentidos e as experiências despertados com participação dos educandos no projeto:

Aluna 6: você falou de significativo e eu lembrei de quando a gente foi na casa do vovô e começou tudo aqui... a gente começou a pegar livros, separamos os livros que a gente poderia levar e lá, teve a interação... você poder ouvir os mais velhos e contar um pouco do que está passando nas escolas, falar um pouco do que está acontecendo em outros lugares... as vezes, eles são abandonados lá... a gente teve um bate papo com as pessoas, fizemos uma roda... e tem horas que eles não conseguiam entender quando a gente falava sobre o amor... Eles contavam um pouco sobre o que era o amor para eles nestes 80 anos de vida... A gente volta renovado, a gente pega um pouco de humanidade...evoluir nossa humanidade pensando que não é só a gente ali... a gente é estudante, tá... legal, estamos na época de zoeira, mas o mundo é muito grande... tem muita coisa pra gente aprender. 


\begin{abstract}
Aluna 3: a gente sai de lá com o olhar mais amplo, sabendo que o mundo não é só você e sua rodinha, que você só se preocupa com aquilo e futilidades... você abre os olhos e vê ao seu redor.

Aluna 7: a leitura amplia nossa visão de mundo, porque quando eu fui para a ADEVIRP eu percebi que o espaço do Djanira em si, o mundo que a gente vive é muito pequeno....a nossa realidade.... foi uma experiência incrível porque as vezes a gente pensa em tantas outras coisas tão bobas e eles, perante a dificuldades... eles tem o sorriso no rosto e ver que a leitura também proporciona prazer para eles, pela alegria da visita e do contato que a gente teve com eles.
\end{abstract}

Aluno 1: muda nosso cotidiano isso, porque a gente visitou mas a gente vai com um certo preconceito de que é, como é...

Aluno 5: acho que mais medo.

Aluna 7: acho que estes projetos, além da ação comunitária que a gente faz também ajuda a desenvolver o nosso senso crítico em relação às muitas falhas que a sociedade apresenta.

A experiência com a leitura (LAROSSA, 2011) torna-se assim, muito mais que um ato mecânico e racional. De todos os projetos citados, este foi o mais significativo na opinião dos educandos da amostra. As descobertas que surgem da relação com outros sujeitos e outros contextos colocam os educandos em situação de abertura à transformação, de questionamentos acerca de seus medos e preconceitos e de formação crítica.

Ler para o outro nunca é apenas oralizar um texto. Ledor e ouvinte dividem mais que a reprodução sonora do escrito, eles compartilham um interesse pelo mesmo texto, uma interpretação construída e conduzida pela voz, além de outras influencias recíprocas que, mesmo não percorrendo os caminhos sugeridos pela ficção, são relações importantes de interação social. (COSSON, 2018, p. 104).

A escolha de idosos e pessoas com deficiência visual favorece a prática da leitura em voz alta como uma forma de sociabilidade e interação, especialmente neste caso, por conta dos problemas de visão e dos impedimentos físicos que tornam a leitura silenciosa uma prática difícil de ser realizada. Neste sentido, dar a conhecer o conteúdo de um texto e proporcionar sociabilidade são algumas das funções da leitura em voz alta. (JEAN, 2000 apud COSSON, 2018, p. 102).

\title{
3.9 Datas comemorativas
}

No projeto direcionado aos alunos dos anos finais do Ensino Fundamental II e do Ensino Médio, o dia da poesia é comemorado com a realização de uma prática denominada "ataque" poético. Os educandos escolhem, previamente, uma obra do acervo e realizam a seleção dos textos para então começar o ataque poético, que consiste na visita surpresa dos educandos que, em grupo, adentram as salas de aula para declamar poesias. No projeto direcionado aos primeiros anos do Ensino Fundamental II, dois são os dias trabalhados pela professora: o dia do índio e o dia do livro infantil, ambos em abril. No dia do índio os alunos confeccionam cocares e fazem uma leitura coletiva de poesias, contos e crônicas na qual a temática indígena é abordada. O dia do livro infantil é comemorado com uma homenagem ao escritor Monteiro Lobato. Os educandos produzem os figurinos dos personagens mais famosos do Sítio do Pica Pau 
Amarelo (Emilia, Narizinho, Tio Barnabé), selecionam e dramatizam alguns diálogos que compõem as obras do autor. Sobre a dramatização como prática de leitura, Cosson afirma

A dramatização enquanto prática de leitura requer a integração de várias linguagens artísticas e vem daí sua importância para a formação do leitor. Junto com a recitação vêm os gestos, a música, o jogo das luzes, as cores e as formas do figurino e do cenário, demandando que a palavra escrita no papel seja traduzida para uma experiência tridimensional. É essa tradução que consiste na interpretação do texto, na leitura literária. (COSSON, 2018, p. 110).

Embora nem sempre focada no aspecto da leitura, a dramatização como prática de leitura promove grande interação entre os educandos, permitindo-lhes expressar os sentidos produzidos pelo texto através dos gestos, dos figurinos e da ação dramática.

Identificadas e descritas as práticas mediadas pela sala de leitura, constata-se que a lógica que movimenta as práticas do Programa Sala de Leitura não se assemelha aos métodos e práticas cotidianas da leitura em sala de aula, caracterizada, na maioria das vezes, pela leitura analítica, pela passividade do sujeito leitor, pela imposição dos temas e por forte didatização do texto. Verificou-se que a participação dos educandos nas práticas não é obrigatória e não segue a lógica avaliativa, ocorre de forma voluntária, ou seja, não há imposições, embora possa ser usada como instrumento de avaliação pelos docentes de todas as disciplinas que desenvolvem projetos em parceria com a sala de leitura. Além disso, é indiscutível a essência coletiva das práticas da sala de leitura Clarice Lispector. A dimensão socializadora das práticas pode, assim, contribuir com a formação de uma comunidade de leitores em torno da leitura literária. Sobre a formação de uma comunidade interpretativa Colomer (2007, p. 148) destaca que

A reflexão educativa já assinalou que o sentimento de pertencer a uma comunidade interpretativa é o mecanismo básico para aprender a desfrutar de formas literárias mais elaboradas (...) trata-se de criar espaços de leitura compartilhada como lugar privilegiado para apreciar os demais e construir sentido entre todos os leitores. (COLOMER, 2007, p. 148).

Em torno dos grupos, os indivíduos podem articular suas referências subjetivas e assumir responsabilidades mútuas ao longo do desenvolvimento das práticas.

Ainda que a possibilidade de escolha esteja subordinada às obras que compõem o limitado acervo, adquiridas através das políticas de distribuição, pode-se afirmar que a instauração do Programa Sala de Leitura, a partir de 2009, introduz na cultura escolar um espaço de liberdade para o sujeito leitor, pois possibilitou a diversificação e a mobilização dos educandos em torno das práticas de leitura. Práticas no âmbito da cultura se estabeleceram no ambiente escolar, fazendo emergir novas configurações para o ato de ler e para as relações dos leitores com a leitura.

Todas essas práticas respondem a variadas formas de interação dos educandos com os textos, fator essencial à formação do jovem leitor. No entanto, apesar dos aspectos positivos relacionados ao envolvimento entusiasmado dos educandos, pode-se sugerir que o Programa Sala de Leitura amplie sua linha de atuação a fim de promover uma leitura mais compreensiva do texto literário, influenciando no processo de formação crítico-ideológica dos leitores mediante práticas que conduzam o leitor ao conhecimento das estratégias de leitura e do diálogo histórico cultural com o texto. 
Observação semelhante fez Ferreira (2016) em sua pesquisa acerca da influência da formação docente no processo de mediação ao concluir que as práticas dos professores mediadores do Programa Sala de Leitura da sua amostra eram conduzidas por abordagens limitadas ao conteúdo dos textos, impedindo que o ato da leitura fosse trabalhado como um ato de linguagem, ou seja, perpassado pelo processo sociocomunicativo de produção de sentidos a partir da interação do leitor com o autor e com o contexto. Como observa Trevizan:

Apesar de valorizar ações gerais de intensa motivação para inserção dos alunos em espaços de convivência com os materiais de leitura (escola, família, feiras culturais), o Programa não coloca em prática os modos críticos de como se deve efetuar uma leitura pragmática dos recursos expressivos das linguagens (dos textos lidos), enquanto veículos ideológicos dos conteúdos identificados. (TREVIZAN, 2017, p. 244).

Neste estudo de caso, considera-se que as práticas viabilizam a interação dos educandos com a leitura e são, de fato, positivas, como demonstram as descrições e as falas dos educandos participantes do grupo focal. Por isso, não se trata de desmerecer as práticas identificadas, mas de sugerir outras em que a leitura seja abordada pela perspectiva da descoberta, da produção de sentidos e da construção da subjetividade a partir da interação com os textos. Trata-se de reforçar, no Programa Sala de Leitura, a noção de que o ato de ler deve ser considerado como um ato discursivo.

$\mathrm{O}$ ato de ler é entendido como um processo discursivo em que os sujeitos produtores de sentido, leitor e autor, são ambos ideologicamente constituídos e sócio-historicamente determinados. A construção dos sentidos é influenciada por esses elementos constitutivos. O texto, nessa perspectiva, é considerado um conjunto de signos "amorfos", isto é, seu sentido só é construído na situação de enunciação, de leitura e não possui significado anterior a ela" (SOUZA; GIROTTO, 2011 ).

Por exemplo, é na sala de leitura que os educandos podem ter a oportunidade de praticar a leitura cursiva, "denominação dada, atualmente, na França, para as leituras pessoais, autônomas e livres de coerção avaliativa". (ROUXEL, 2012, p. 272). Segundo a autora, a introdução da leitura cursiva nos programas das escolas francesas inicia-se em 2001 e pode ser analisada como uma "resposta institucional à falência do modelo de leitura analítica em vigor". (ROUXEL, 2012, p. 276). Desta forma, a prática de uma leitura mais flexível e livre convida o leitor a uma apropriação singular das obras, favorecendo outra relação com o texto. A leitura cursiva pode incentivar o educando a participar de práticas que reconheçam a subjetividade do leitor. Rouxel (2012, p. 281) sugere as seguintes práticas:

a. incentivar a expressão do julgamento estético, convidando o aluno a se exprimir sobre seu prazer ou desprazer em relação à leitura;

b. acolher os afetos dos alunos e de incentivá-los na descoberta de dilemas pessoais na leitura;

c. encorajar as abordagens sensíveis das obras, atentar para a recepção dos alunos ou daquilo que eles aceitarão manifestar de sua experiência estética; 
d. abertura do consenso ao plural das interpretações.

Estas sugestões podem ampliar o repertório das práticas oferecidas na sala de leitura. Para isso, é importante que se estabeleçam práticas em que a relação dos educandos com o texto não seja de submissão, pois devem permitir ao leitor adentrar com profundidade na produção dos sentidos possíveis que permeiam os textos. É preciso aceitar o leitor como sujeito que reconstrói o texto a partir de suas leituras subjetivas.

Em suma, aceitar a expressão da subjetividade do leitor nas experiências de leitura. Além disso, seria interessante que os educandos tivessem mais oportunidades para frequentar a sala de leitura, até mesmo durante o tempo regular, objetivando a realização diária de uma leitura silenciosa sustentável (COSSON, 2018, p. 99). Assim, os educandos teriam diariamente em torno de vinte minutos da aula reservados à prática da leitura silenciosa sustentável. No entanto, Colomer nos aconselha cautela se considerarmos que as condições de leitura na escola estão longe de permitir total liberdade ao educando leitor:

Devemos lembrar que a leitura na escola nunca é livre por completo. Há um tempo limitado, um lugar determinado, condições de leitura e um sistema de regras acertadas (tempo máximo para escolher um livro antes de sentar-se para ler, possibilidades de empréstimo, formas de solicitação de apoio ao docente para prosseguir a leitura, etc.), que fazem com que se trate apenas de uma leitura parecida com a que se realiza socialmente por prazer. (COLOMER, 2007, p. 127).

Ainda assim, oferecer a oportunidade de realizar uma leitura livre ao término das atividades da sala de aula ou a determinar um horário permanente na grade curricular pode fazer da sala de leitura um espaço de aproximação entre os educandos e o gosto pela leitura. Apesar da simplicidade, existem condições para que prática da leitura silenciosa sustentável aconteça de forma positiva. Segundo Cosson (2018, p. 100), para a realização da prática da leitura silenciosa sustentável é importante que se tenha um ambiente descontraído, um acervo que desperte o interesse e agrade o gosto do leitor, bem como o apoio da direção e do corpo pedagógico da escola no sentido de legitimar este modo de ler no ambiente escolar.

De acordo com Rojo (2004), diferentes práticas de leitura, em diversas situações, vão exigir diferentes combinações de capacidades - capacidades de decodificação, capacidades de compreensão; capacidades de apreciação e réplica do leitor em relação ao texto. As capacidades de decodificação, que em geral são ensinadas e aprendidas durante o processo de alfabetização, nas séries iniciais do Ensino Fundamental I, relacionam-se ao conhecimento do alfabeto, das relações entre grafemas e fonemas e ao saber decodificar palavras e textos escritos. (ROJO, 2004, p.4).

As capacidades de compreensão relacionam-se a capacidade do leitor em utilizar estratégias cognitivas e metacognitivas durante a leitura. As estratégias de leitura devem ser objeto de atenção nos processos de mediação, pois o domínio destas competências garante autonomia de pensamento e compreensão. Ativar seus próprios conhecimentos de mundo, previamente à leitura ou durante, é uma das estratégias que o leitor utiliza na busca pela compreensão. O leitor está "constantemente colocando em relação seu conhecimento amplo de mundo com aquele exigido e utilizado pelo autor no texto." (ROJO, 2004, p.5). Outra estratégia é antecipação ou predição de conteúdos ou propriedades dos textos: O leitor considera a situação de leitura, suas finalidades, $\mathrm{o}$ contexto em que ela se dá; o suporte do texto, a disposição da página; do título, das 
fotos. O leitor levanta hipóteses tanto sobre o conteúdo como sobre a forma do texto. (ROJO, 2004, p.5). Além disso, a checagem de hipóteses é outra estratégia, pois constantemente o leitor estará checando, confirmando-as ou contradizendo-as e, consequentemente, buscando novas hipóteses mais adequadas.

Operando junto a outras práticas, a localização e/ou cópia de informações é uma estratégia básica de muitas práticas de leitura: para estudar, para trabalhar, para buscar informações, o "leitor está constantemente buscando e localizando informação relevante, para armazená-la - por meio de cópia, recorte-cole iluminação ou sublinhado - e, posteriormente, reutilizá-la de maneira reorganizada." (ROJO, 2004, p.5). Por fim, estratégias como: comparar informações de várias ordens, advindas do texto, de outros textos, de seu conhecimento de mundo; elaborar generalizações e conclusões gerais; produzir inferências locais, isto é, pelo contexto imediato do texto, e inferências globais, ou seja, dos implícitos ou pressupostos de um texto; também são estratégias que dizem respeito às capacidades de compreensão que são colocadas em jogo no ato da leitura. (ROJO, 2004, p.5).

A capacidade denominada por Rojo (2004) de apreciação e réplica do leitor em relação ao texto trata da interpretação resultante da interação entre a tríade leitor-textoautor. Uma das estratégias aplicadas para levar a cabo o desenvolvimento destas capacidades é a recuperação do contexto de produção do texto, situando:

(...) quem é seu autor? Que posição social ele ocupa? Que ideologias assume e coloca em circulação? Em que situação escreve? Em que veículo ou instituição? Com que finalidade? Quem ele julga que o lerá? Que lugar social e que ideologias ele supõe que este leitor intentado ocupa e assume? Como ele valora seus temas? Positivamente? Negativamente? Que grau de adesão ele intenta? Sem isso, a compreensão de um texto fica num nível de adesão ao conteúdo literal, pouco desejável a uma leitura crítica e cidadã. Sem isso, o leitor não dialoga com o texto, mas fica subordinado a ele. (ROJO, 2004, p.6).

O desenvolvimento das capacidades de apreciação e réplica implica que o leitor defina o propósito de sua leitura, pois todo o "controle do processo de leitura, da ativação de estratégias ou do exercício de capacidades está subordinado às metas ou finalidades de leitura impostas pela situação em que o leitor se encontra." (ROJO, 2004, p.6). Além da apreensão de outras linguagens como elementos constitutivos dos sentidos dos textos e não somente da linguagem verbal escrita, perceber as relações de intertextualidade é uma estratégia que consiste em colocar o texto em relação com outros textos já conhecidos, a partir dos temas ou conteúdos abordados. Nas relações de interdiscursividade, a estratégia é "perceber o discurso é colocá-lo em relação com outros discursos já conhecidos, que estão tecidos por este discurso". (ROJO, 2004, p.6).

Por fim, as duas últimas estratégias que auxiliam no desenvolvimento das capacidades de apreciação e réplica do leitor em relação ao texto relacionam-se à elaboração de apreciações estéticas e/ou afetivas e de apreciações relativas a valores éticos e/ou políticos. A primeira trata de como reagimos ao texto estética e afetivamente: se sentimos prazer ou se apreciamos a forma de expressão da linguagem do autor, por exemplo. A segunda trata das discordâncias e concordâncias, das críticas e dos posicionamentos ideológicos colocados em circulação no texto. Segundo Rojo (2004, p. 7), esta "capacidade é que leva a uma réplica crítica a posições assumidas pelo autor no texto". 
Sendo assim, como o Programa Sala de Leitura pressupõe a atuação de um professor na mediação entre o acervo e os educandos através do planejamento e da oferta de práticas de leitura, essas capacidades podem integrar os processos e práticas do professor da sala de leitura a fim de contribuir com a formação de um leitor competente e crítico. Complementando a perspectiva acima, outra sugestão que visa o fortalecimento do Programa Sala de Leitura refere-se ao planejamento de práticas que se fundamentam no uso da metodologia das estratégias de leitura (GIROTTO; SOUZA, 2010) e (SOUZA; GIROTTO, 2011). Em seu conjunto, as estratégias de leitura devem permitir ao leitor desenvolver habilidades para realizar conexões, inferências, visualizações, questionamentos, sínteses e sumarizações relativos ao texto lido.

Neste caso, em especial, o processo de mediação e ensino se aliam em beneficio da formação de um leitor critico, competente e autônomo. O professor não apenas medeia, mas interfere intencionalmente e com objetivos definidos em um ensino explicito e reflexivo tal como defendem Souza e Girotto (2011, p. 12). Trata-se de creditar ênfase às relações sociais de aprendizagem que, mediadas pela linguagem, conferem uma perspectiva sociocultural ao processo de desenvolvimento do indivíduo.

As sete habilidades ou estratégias utilizadas no ato de leitura - conhecimento prévio, conexão, inferência, visualização, perguntas ao texto, sumarização e síntese (PRESSLEY, 2002 apud SOUZA; GIROTTO, 2011) - não seguem uma ordem de execução no pensamento, podendo ser ativadas conjuntamente. No entanto, durante o processo de ensino, o professor mediador "agirá didaticamente, explicando-os conforme surgem no decorrer da leitura do texto". (SOUZA; GIROTTO, 2011, p. 14). Por exemplo, a professora que lê histórias em voz alta e faz mediações (comenta e relaciona texto e ilustrações) favorece a construção de habilidades de compreensão de textos e a familiaridade com a escuta do texto escrito.

Quando a professora explicita os motivos pelos quais escolheu determinado texto para ler, está mediando uma informação que orienta os alunos na compreensão dos propósitos da leitura. O sentido da leitura é produto também da interação entre interlocutores e da situação em que estão inseridos, sendo a mediação do professor fundamental. A fim de auxiliar o educando a dominar as numerosas estratégias de leitura, Girotto e Souza (2010) sugerem uma proposta didática denominada Oficina de Leitura, sendo possível também serem aplicadas na prática do Círculo de Leitura (COSSON, 2018) e nas práticas semelhantes, identificadas no artigo, como a Roda de Leitura e do Projeto Constelação.

O ponto de partida da Oficina de Leitura é a aula introdutória (GIROTTO; SOUZA, 2010, p. 61), momento em que o professor delineia as estratégias de compreensão do texto que serão desenvolvidas ao longo da prática. Neste momento, a prática é guiada pelo professor e seu o papel é promover a leitura em voz alta, elaborando simultaneamente comentários acerca de como os atos do pensamento que podem organizar e constituir a compreensão do texto, contribuindo com o processo de atribuição de sentidos ao texto. Na segunda etapa da oficina, os educandos, organizados em grupos de três a seis indivíduos, mobilizam-se em torno da leitura partilhada de um texto. Ao professor cabe motivar a discussão, conduzindo os grupos a falar, pensar e escrever sobre o que leram ao mesmo tempo em que retoma o uso explícito e reflexivo das estratégias de leitura.

Em seguida, os educandos tem a oportunidade de praticar a leitura independente, ou seja, leem individualmente e silenciosamente tentando aplicar sozinhos as estratégias. (GIROTTO; SOUZA, 2010, p. 63). Por fim, a avaliação da prática, quando o professor examina a qualidade do entendimento acerca das estratégias por parte do educando, retomando, a partir de discussões orais, cartazes sínteses ou gráficos 
organizadores, o "processo de leitura a fim de verificar o quê, para quê, como e em que momento os alunos utilizaram a referida estratégia de leitura" (GIROTTO; SOUZA, 2010, p. 63).

A partir das excelentes sugestões de Girotto e Souza (2010), a seguir, serão exemplificadas práticas que orientam como o professor pode levar o educando a pensar seu próprio processo de leitura a partir do acionamento das estratégias de estabelecer conexões e fazer inferências acerca de um texto.

Fazer conexões e ativar o conhecimento prévio são estratégias realizadas naturalmente, mas que é preciso evidenciá-las e ensiná-las a fim de os educandos possam usar intencionalmente quando imersos em práticas de leitura. Segundo Girotto e Souza (2010, p. 68-69) há três tipos de conexões possíveis: conexão texto-leitor (leitor estabelece conexões com sua própria vida), conexão texto-texto (leitor estabelece relações com outros textos) e conexão texto-mundo (leitor estabelece conexões com acontecimentos globais).

Nas práticas sugeridas por Girotto e Souza (2010, p. 71-74) que visam o uso de estratégias de conexão é possível:

a) relacionar personagens e situações de um texto com a vivências do próprio leitor;

b) relacionar temas e ideias em comum entre livros da mesma autoria ou livros e outros matérias de leitura verbal e não verbal do mesmo tema; comparando personagens, situações, ensinamentos implícitos nos textos;

c) relacionar acontecimentos e fatos que perpassam a vida em sociedade e a história da humanidade a fim de estruturar o entendimento da obra.

A elaboração de inferências é outra estratégia de compreensão que leitores ativam durante a leitura. Deduzir durante a leitura de um texto verbal ou não verbal "requer uma conclusão ou interpretação que não está explícita no texto" (GIROTTO; SOUZA, 2010, p. 76). A ativação dos conhecimentos prévios é parte do processo de elaboração de inferências. A partir da mobilização dos conhecimentos prévios, leitores inferem, estabelecem expectativas do que vai acontecer; antecipam e preveem que informações o texto irá conter.

Girotto e Souza (2010, p. 77-82) sugerem aos professores três práticas para ensinar o educando a produzir inferências durante o ato de ler. A primeira prática é inferir o significado das palavras desconhecidas a partir das dicas do próprio texto. $\mathrm{O}$ professor incentiva o educando a perceber aspectos do contexto do texto (imagens, textura, palavras e frases destacadas) que possibilitam inferir o significado de uma palavra. Os educandos podem produzir uma folha do pensar que facilite o registro das relações entre a palavra desconhecida, o significado inferido, e a frase que traz a dica. (GIROTTO; SOUZA, 2010, p. 79).

\begin{tabular}{|c|c|c|c|}
\hline $\begin{array}{c}\text { Palava } \\
\text { desconhecida }\end{array}$ & $\begin{array}{c}\text { Significado } \\
\text { Inferido }\end{array}$ & $\begin{array}{c}\text { Dicas } \\
\text { do texto }\end{array}$ & $\begin{array}{c}\text { Frases } \\
\text { do livro }\end{array}$ \\
\hline
\end{tabular}

Adaptado de GIROTTO; SOUZA, 2010, p. 79.

A segunda prática é inferir pela capa e ilustrações, "com o intuito de usar todos os aspectos de um livro para descobrir significados" (GIROTTO; SOUZA, 2010, p. 80). Nesta prática os educandos podem registrar suas inferências em um quadro recapitulativo: 
\begin{tabular}{|r}
\hline Citação ou gravura do texto \\
Adaptado de GIROTTO; SOUZA, 2010, p. 80.
\end{tabular}

A terceira e última prática é "reconhecer o enredo e inferir os temas da narrativa" (GIROTTO; SOUZA, 2010, p. 82). O reconhecimento das tramas da estória, das sequências dos fatos e das situações vividas pelos personagens podem auxiliar os educandos a inferir os temas e as ideias da narrativa. $\mathrm{O}$ educando pode organizar seu pensamento em um cartaz onde serão registrados os temas inferidos a partir das evidências e das dicas contidas no enredo.

Com pode-se perceber, a aquisição da leitura e, consequentemente, de todas as capacidades inerentes ao ato de ler, não são procedimentos naturais ao ser humano. Apenas em situação de mediação e aprendizagem o educando é capaz de fomentar a internalização das capacidades de decifração, compreensão e interpretação envolvidas no ato da leitura. Por isso, a importância do professor, do mediador de leitura e do bibliotecário como agentes ativos da criação de práticas de mediação e de ensino. Essa é a potencialidade do Programa Sala de Leitura.

As práticas de leitura colocam o ser humano em processo de interação com os signos e todos os significados e sentidos que lhes possam ser atribuídos, contribuindo com a formação dos processos psicológicos superiores e sendo por eles apoiadas, em um movimento dialético. Ou seja, a prática da leitura tanto desenvolve quanto depende da atenção voluntária, da percepção, da memória e do pensamento, capacidades que, para serem apropriadas, necessitam de uma situação ou uma prática intencionalmente planejada. Desta forma, é preciso a presença do outro auxiliando na mediação dos conhecimentos estruturados no âmbito interpsicológico a fim de que se internalizem o no intrapsicológico do sujeito. A partir disso, reconhece-se que formar cidadãos leitores implica a necessidade da presença constante do outro no planejamento e na oferta de práticas de leitura que contemplem as diferentes capacidades e estratégias que envolvem o ato da leitura.

Nenhuma das práticas aqui citadas tem capacidade de promover, por si só, a formação de leitores. Tanto as práticas sociais de leitura quanto as práticas cotidianas da leitura escolar podem contribuir com a formação do jovem leitor. É possível que a combinação das práticas já realizadas pela sala de leitura Clarice Lispector e das práticas aqui sugeridas formem um conjunto coerente de procedimentos que visam embasar programas de leitura nos ambientes escolares. A sala de leitura pode ser pensada, então, como lugar de emergência e confrontação de leituras subjetivas, mantendo a porta aberta à expressão do sujeito na coletividade, ao mesmo tempo em que orienta o desenvolvimento metacognitivo relacionado à apropriação das estratégias de leitura. Em suma, acredita-se que é possível ampliar significativamente a contribuição do Programa Sala de Leitura na formação do leitor competente através da implantação de práticas de leitura literária que se complementam e que permitam:

a) o desenvolvimento de habilidades e estratégias de leitura para a compreensão de textos;

b) o desenvolvimento do gosto pela leitura;

c) a leitura como possibilidade de construção de sentidos e das funções psicológicas superiores;

d) o compartilhamento tanto de apreciações estéticas e afetivas quanto relativas a valores éticos ou políticos das obras que perpassam o cotidiano escolar dos educandos; 


\section{Considerações Finais}

Completando dez anos de existência, o Programa Sala de Leitura nasceu comprometendo-se, pelas vias da lei, em ser um espaço privilegiado de incentivo à leitura como fonte de informação, prazer, entretenimento e formação de leitor crítico, criativo e autônomo. Assim, pode-se afirmar que o estabelecimento do Programa Sala de Leitura foi uma iniciativa positiva, se levado em consideração que antigas bibliotecas escolares das escolas estaduais paulistas eram abandonadas e trancafiadas.

Seguindo o pressuposto de que em comunicação com o outro, mediados pela linguagem, são configurados os aspectos intrapsicológicos humanos, a hipótese deste artigo, fundamentada na ideia de que o Programa Sala de Leitura pode contribuir com a formação leitora dos educandos, é confirmada, especialmente através da atuação da professora em sua função de mediadora de práticas de leitura. Os resultados confirmaram contribuições significativas do Programa Sala de Leitura no que se refere à mobilização, envolvimento e motivação dos educandos em práticas de leitura literária devido à atuação mediadora de uma professora.

No entanto, permitiram, ao mesmo tempo, revisões críticas sobre a necessidade de atualização das práticas ofertadas para que, de fato, elas possibilitem a formação de leitores críticos, competentes e autônomos. Sendo assim, a contribuição do Programa Sala de Leitura para a formação leitora dos educandos apresenta limites.

Se o objetivo do Programa Sala de Leitura é mesmo formar leitores críticos e autônomos, podem-se incluir outras práticas voltadas para a leitura como fonte de informação, para momentos de leitura livre e silenciosa, bem como para a aprendizagem de estratégias de leitura. As estratégias de leitura podem ser incluídas em práticas que coloquem os sujeitos do processo ensino-aprendizagem em diálogo entre si, motivados pelo texto e assumindo uma perspectiva interacionista de compreensão e construção de sentidos, a partir da influência do outro (autor e sujeitos envolvidos nas práticas) e dos signos linguísticos na construção do pensamento, como é o caso dos círculos de leitura (COSSON, 2018) e das oficinas de leitura (GIROTTO; SOUZA, 2010), por exemplo.

$\mathrm{Na}$ perspectiva da Teoria Histórico Cultural, instrumentos e signos são elementos mediadores da relação entre o indivíduo e o mundo. Colocando o livro e a leitura em correspondência a esta perspectiva, temos que o livro corresponde a um objeto social, um instrumento criado pelo ser humano capaz de interferir na natureza cultural e na transmissão desta para as gerações futuras. E a leitura, enquanto produto da relação sígnica entre palavras e pensamento, enquadra-se como um instrumento que mobiliza a atividade psicológica, auxiliando no desenvolvimento das funções psicológicas superiores. A leitura, como um trabalho sígnico com a linguagem, contribui com o processo de internalização das funções psicológicas superiores e, consequentemente, com a capacidade de criar representações mentais dos objetos e da realidade que circunda a vida humana.

É na escola que grande parte da população tem garantido o acesso ao ensino da leitura e o contato com a leitura literária, seja através das práticas curriculares pertinentes à sala de aula, seja através das práticas promovidas pelas bibliotecas escolares ou das salas de leitura. O fato é que o processo de construção do conhecimento nos indivíduos é um fenômeno profundamente social, pois são as experiências que vivenciamos no constante contato com o outro que delineiam as possibilidades de aquisição dos meios disponíveis para pensar e interpretar o mundo, sendo a linguagem o principal elemento de mediação deste processo. 
Por isso, é possível concluir que, aliando as práticas já existentes com as práticas sugeridas, o Programa Sala de Leitura potencializa a formação e o desenvolvimento da linguagem nos indivíduos, pois, a partir da promoção da interação entre os educandos e as obras literárias, os professores desempenham um importante papel no que diz respeito à ação mediadora de práticas que visam à formação de leitores. Nesta mesma perspectiva, encontram-se as bibliotecas, seus bibliotecários e cientistas da informação, instituições e profissionais tão importantes quanto as escolas e seus professores quando o assunto é formação de leitores.

\section{Referências}

BATISTA, A. A. G.; GALVÃO, A. M. O. Práticas de leitura, impressos, letramentos: uma introdução. In: GALVÃO, A. M. O; BATISTA, A. A. G. (Orgs). Leitura: práticas, impressos, letramentos. Belo Horizonte: Editora Autêntica, 2011. p. 11-48.

CHARTIER, R. (Org.) Práticas da Leitura. 5. ed. São Paulo: Estação Liberdade, 2011.

COLOMER, T. Andar entre livros: a leitura literária na escola. Trad. Laura Sandroni. São Paulo: Global, 2007.

COSSON, R. Letramento literário: teoria e prática. 2. ed. São Paulo: Contexto, 2018.

FERREIRA, H. O perfil do professor como responsável pelo "Programa Sala de Leitura" em escolas públicas de uma cidade do Oeste Paulista: formação docente e práticas de mediação. 2016. 158 fs. Dissertação (Mestrado em Educação) Universidade do Oeste Paulista, Presidente Prudente, SP.

GIROTTO, C. G. G. S; SOUZA, R. J. Estratégia de leitura: para ensinar alunos a compreender o que leem. In: SOUZA, R. J. et al. Ler e compreender: estratégias de leitura. Campinas: Mercado das Letras, 2010. p. 45-114.

LAROSSA, Jorge. Experiência e alteridade em educação. Revista Reflexão e Ação, Santa Cruz do Sul, v.19, n. 2, jul./dez. 2011. Disponível em: http://online.unisc.br/seer/index.php/reflex/article/view/2444/1898. Acesso em: 5 ago. 2019.

OLIVEIRA, M. K. Vygostsky aprendizado e desenvolvimento: um processo sóciohistórico. 4. ed. São Paulo: Scipione, 2011.

ORLANDI, E. P. Discurso e leitura. São Paulo: Ed. UNICAMP: Cortez, 1988.

ROJO, R. Letramento e capacidades de leitura para a cidadania. São Paulo: SEE: CENP, 2004.

ROUXEL, A. Práticas de leitura: quais rumos para favorecer a expressão do sujeito leitor? Cadernos de Pesquisa, São Paulo, v. 42, n. 145, p. 272-283, abr. 2012. Disponível em: http://www.scielo.br/scielo.php?script=sci_arttext\&pid=S0100$15742012000100015 \& \operatorname{lng}=e n \& n r m=$ iso. Acesso em: 17 jul. 2019. 
SOUZA, R. J; GIROTTO, C. G. G. S. Estratégias de leitura: uma alternativa para o início da educação literária. Álabe: revista de la red de universidades lectoras, n.4, dez. 2011. Disponível em: http://www.ual.es/alabe. Acesso em: 3 ago. 2019.

TREVIZAN, Z. Saberes científicos e epistemologia da prática nos processos institucionais de formação docente e de formação de leitores. Perspectiva, Florianópolis, v. 35, n. 1, mês jan./mar., 2017. Disponível em: /https://periodicos.ufsc.br/index.php/perspectiva/article/viewFile/2175795X.2017v35n1 p237/pdf / Acesso em: 9 ago. 2019.

VYGOTSKY, L. S; LURIA, A. R; LEONTIEV, A. N. Linguagem, desenvolvimento e aprendizagem. 14 ed. São Paulo: Ícone, 2016.

Recebido em 22 de agosto de 2019

Aceito em 27 de novembro de 2019 